\section{Dr. Harrington replies}

\section{To the Editor:}

The information provided by Dr. Bernatsky and colleagues in response to Graydon and Thompson's report ${ }^{1}$ and my accompanying editorial ${ }^{2}$ is appreciated. Their observation that patients may delay seeking medical care for early rheumatoid arthritis (RA) relates to a different problem than we were addressing: the ineffective evaluations and delays in referral by providers once the patient is seen.

Like all stakeholders in healthcare, physicians typically deflect responsibility for problems from themselves onto others ${ }^{3-5}$. So the use of focus groups to explore provider attitudes is unlikely to yield helpful data regarding the root causes of health system underperformance. Moreover, the resistance of patients from rural areas and lesser financial circumstances to specialty consultation should not be generalized.

Dr. Bernatsky and the focus group physicians also believe that educating primary physicians about the diagnosis and management of early RA will improve patient care. My dismissing this approach may seem "harsh and self-defeating," but I suggest that this solution has already failed. If physicians do not provide effective diagnosis and referral after many years of undergraduate, postgraduate, and continuing medical education, why should more of the same make a difference? The high variance in care among physicians for the same problem is not due to knowledge deficits; it resides in ineffective delivery of care.

Indeed, many studies have shown that provider education has only a modest effect on the outcomes of chronic diseases in comparison to practice and system-process changes ${ }^{6,7}$. Referral of patients to a musculoskeletal screening clinic is one of the intriguing redesigns referenced by Graydon and Thompson, and that might rapidly improve referral performance ${ }^{8}$, but it would require cooperation among primary physicians, orthopedic surgeons, and rheumatologists at the health system or regional level.

A key finding of Graydon and Thompson's review of referring physicians' records is that they are generally limited to a pain complaint and laboratory tests, while seldom including a more detailed history or joint examination. This latter information is the key to identifying patients with a higher probability of early inflammatory arthritis, and is the basis for the Emory criteria referenced in my editorial. Why are primary care training programs not teaching this? Moreover, the laboratory tests that are widely ordered for patients with musculoskeletal symptoms are useless or misleading, run up the cost of healthcare, and correlate poorly with pretest probabilities.

This having been said, the fundamental problems are that the patient with early RA is a needle in a haystack among a throng of patients with musculoskeletal symptoms, and that the disease often begins gradually, with symptoms that are indistinguishable from those of other disorders. So diagnostic uncertainty is high, evaluation is time-consuming, and patients' symptoms must often be managed in the face of these realities. Patients can hardly be held accountable for failing to recognize their risk at the onset of symptoms under these circumstances, and few health systems have a reliable process for managing this population, one that coordinates the expertise of consultants and the point of care role of primary physicians.

Solving this problem must begin with a clear look at the realities of health system underperformance and the evidence of what works and what doesn't. Primary physicians' appropriate role must be to identify those patients with a significant probability of early inflammatory arthritis based on an efficient history and examination, and to refer them — not draw labs, try to diagnose them, or initiate treatment. At the same time, they must become more capable of diagnosing and managing the patients with selflimited local musculoskeletal symptoms that clog the consultants' newpatient appointments, and keep in mind that a few of these may develop into recognizable inflammatory arthritis.

J.T. HARRINGTON, MD, University of Wisconsin School of Medicine and Public Health, One South Park Street, Madison, Wisconsin 53715, USA. E-mail: tim.harrington@uwmf.wisc.edu

\section{REFERENCES}

1. Graydon SL, Thompson AE. Triage of referrals to an outpatient rheumatology clinic: analysis of referral information and triage. J Rheumatol 2008;35:1378-83.

2. Harrington T. Improving access to rheumatology care: a continuing challenge. J Rheumatol 2008;35:1233-4.

3. Phillips LS, Branch WT, Cook CB, et al. Clinical inertia. Ann Intern Med 2001;135:825-34.

4. Porter ME, Teisberg EO. Redefining health care: creating value-based competition on results. Boston: Harvard Business School Press; 2006.

5. Porter ME, Teisberg EO. How physicians can change the future of health care. JAMA 2007;297:1103-11.

6. Lawrence DM. Chronic disease care: rearranging the deck chairs. Ann Intern Med 2005;143:458-9.

7. Shojania KG, Ranji SR, McDonald KM, et al. Effects of quality improvement strategies for type 2 diabetes on glycemic control: a meta-regression analysis. JAMA 2006;296:427-40.

8. Gormley GJ, Steele WK, Gilliland A, et al. Can diagnostic triage by general practitioners or rheumatology nurses improve the positive predictive value of referrals to early arthritis clinics? Rheumatology Oxford 2003;42:763-8.

J Rheumatol 2009;36:4; doi:10.3899/jrheum.080944 